\title{
Impaired Cell-Mediated Immunity in Hodgkin's Disease Mediated by Suppressor Lymphocytes and Monocytes
}

\author{
Stephen M. Hillinger and Geoffrey P. Herzig, Division of Hematology- \\ Oncology, Department of Internal Medicine, Washington University School of \\ Medicine, St. Louis, Missouri 63110
}

A B S T R A C T In Hodgkin's disease a possible mechanism for impaired cellular immunity is cell-mediated suppression, defined as the inhibitory interaction between suppressor cells and effector lymphocytes. To test for the presence of suppressor cells in peripheral blood, we have modified the standard, one-way mixed lymphocyte culture by adding mitomycin C-treated mononuclear cells from the responder. Suppression, expressed as a percent of the base-line mixed lymphocyte culture in which these extra cells are not present, results in a reduction of thymidine incorporated in the modified culture (i.e., $100 \%$ suppression $=$ no net thymidine incorporation; $0 \%$ suppression = identical thymidine incorporation in both the modified and baseline culture).

Suppression was found to be significantly increased in patients with both active Hodgkin's disease (78 $\pm 4.6 \%)$ and remission Hodgkin's disease $(58 \pm 9.3 \%)$ compared to normal individuals $(21 \pm 6.9 \%)$ (mean $\pm \mathrm{SE}$ ). The degree and frequency of suppression were not influenced by disease stage or prior therapy. Cell purification techniques revealed (in 10 patients studied) the suppressor cell to be a monocyte in 6 , and a thymus-derived lymphocyte in 4 . Possible genetic restriction of the suppressor cell interaction was indicated by a failure of suppressor cells to alter the response of lymphocytes from unrelated individuals, but suppression was obtained with lymphocytes from a histocompatible sibling. Although mononuclear cells from normal individuals suppress less frequently than cells from patients with Hodgkin's disease, normals may demonstrate suppression comparable to that observed in Hodgkin's patients. This finding suggests

Portions of this work were presented at the American Association for Cancer Research, Denver, Colo., 18 May 1977.

Dr. Herzig is a Scholar of the Leukemia Society of America. Dr. Hillinger's present address is the Division of Oncology, Albany Medical College of Union University, Albany, N. Y. 12208.

Received for publication 23 June 1977 and in revised form 22 December 1.977. that suppression is a normal immunoregulatory mechanism which is altered in Hodgkin's disease.

\section{INTRODUCTION}

Patients with Hodgkin's disease, both active and in remission, frequently have impaired cell-mediated immunity as demonstrated by anergy to recall skin tests (1-3), failure of dinitrochlorobenzene sensitization (4), prolonged skin allograft survival $(3,5)$, and impaired immunity after BCG vaccination (6). Lymphocyte function in vitro is also impaired as measured using mitogen (phytohemagglutinin, concanavalin $\mathrm{A}$, and pokeweed mitogen), and antigen responsiveness $(1,2,7,8)$, as well as stimulation and proliferation in mixed lymphocyte cultures $(9,10)$. It has been suggested that the reduced cellular immunity can be explained by a diminished number of thymus-derived lymphocytes ( $T$ lymphocyte), and both lymphopenia and diminished percentages of $\mathrm{T}$ lymphocytes have been described in some Hodgkin's disease patients $(11,12)$. However, these findings correlate poorly with other parameters of immune function (1). Recently, Fuks et al. have demonstrated a serum factor in Hodgkin's disease that interferes with the formation of sheep erythrocyte rosettes (E rosettes) ${ }^{1}$ by $\mathrm{T}$ lymphocytes, but its clinical significance remains to be established (13).

Another possible mechanism for impaired immunity in Hodgkin's disease involves cell-mediated suppression. Cells that mediate suppression exert an inhibitory effect on the function of effector lymphocytes. Suppressor cells have been characterized in a variety of animal models and have been shown to be responsible for impaired humoral immunity in some patients with common variable hypogammaglobulinemia $(14,15)$ and multiple myeloma (16). Both T lymphocytes and monocytes have been shown to have suppressor func-

\footnotetext{
${ }^{1}$ Abbreviations used in this paper: E rosette, sheep erythrocyte rosettes; HBSS/albumin, Hanks' balanced salt solution/ salt-poor human serum albumin; MLC, mixed lymphocyte culture; TC 199, tissue culture Medium 199.
} 
tion. In Hodgkin's disease mononuclear cells from patients of advanced stage may contain suppressor cells that are responsible for both poor phytohemagglutinininduced proliferation (17) and impaired stimulation in mixed lymphocyte culture (10).

We have examined the possibility that increased suppressor cell activity may be more common than presently appreciated in Hodgkin's disease patients. With a modification of the standard one-way mixed lymphocyte culture, we have found increased suppression of lymphocyte proliferation, mediated by either $\mathrm{T}$ lymphocytes or monocytes, in the majority of patients with active and remission Hodgkin's disease. This suppressive effect, which can occur to a lesser degree in normal individuals, appears genetically restricted to autologous, and to histocompatible, cellular interactions.

\section{METHODS}

Subjects. The study group consists of 23 unselected, consecutively studied patients with Hodgkin's disease (13 male, 10 female), age ranging from 18 to $75 \mathrm{yr}$, seen at Barnes Hospital, St. Louis, Mo. between 1976 and 1977. 14 patients had active disease; 9 of these were previously untreated. The remaining five patients with active disease all had prior treatment with radiation therapy, and all but one with prior chemotherapy. Nine patients with Hodgkin's disease in clinical remission of at least $6 \mathrm{mo}$ also were studied. All patients were off therapy for a minimum of $6 \mathrm{wk}$ before study.

Histologic classification of Hodgkin's disease was made according to the Rye Conferences modification (18). Patients were staged in accord with the recommendations of the Ann Arbor Conference (19).

The control population consists of 19 normal, healthy volunteers ( 8 male, 11 female) with an age ranging from 16 to $45 \mathrm{yr}$.

Mononuclear cell preparation. Mononuclear cells were prepared by density sedimentation of heparinized blood over Ficoll (Sigma Chemical Co., St. Louis, Mo.) sodium diatrizoate (Hypaque sodium, $50 \%$, Winthrop Laboratories, New York), by a minor modification of Böyum's technique (20), and thrice washed in Hanks' balanced salt solution (HBSS, Grand Island Biological Co., Grand Island, N. Y.) plus 1\% (vol:vol) saltpoor human serum albumin (HBSS/albumin, Parke, Davis \& Co., Detroit, Mich.).

Mononuclear cells were resuspended in tissue culture media consisting of $78 \mathrm{ml}$ of Medium 199, $1 \mathrm{ml} \mathrm{L-glutamine} \mathrm{(200}$ $\mathrm{mM}), 1 \mathrm{ml}$ penicillin $(1,000 \mathrm{U}) /$ streptomycin $(10,000 \mu \mathrm{g})$ (all obtained from Grand Island Biological Co.), and $20 \mathrm{ml}$ human plasma from normal individuals (TC 199/20\% plasma). Proliferation of cells designated for subsequent use as either stimulators or suppressors in mixed lymphocyte culture was prevented by treatment with mitomycin C (Sigma Chemical Co.). The cells were incubated with mitomycin $\mathrm{C}(50 \mu \mathrm{g} / \mathrm{ml})$ for $30 \mathrm{~min}$ at $37^{\circ} \mathrm{C}$ and then washed twice in HBSS/albumin. Alternatively, when mononuclear cell recovery was small, proliferation was inhibited by irradiation with 2,000 rads from a ${ }^{131}$ Cs source (Gamma Cell-20 Small Animal Irradiator, Atomic Energy of Canada, Ltd., Ottawa, Canada), before culturing.

Removal of adherent cells. Nylon wool filters were made with a modification of the method of Mendelsohn et al. (21). Mononuclear cells suspended in Medium 199/10\% heat-inactivated fetal calf serum (Grand Island Biological Co.), were incubated on the filters at $37^{\circ} \mathrm{C}$ for $30 \mathrm{~min}$. Nonadherent cells were eluted from the filters with Medium 199/10\% FCS warmed to $37^{\circ} \mathrm{C}$, washed twice in $\mathrm{HBSS} /$ albumin, and resuspended in TC 199/20\% plasma. The nonadherent population contained fewer than $1 \%$ monocytes as judged by microscopic examination of blood films stained supravitally with Janus green and neutral red (22).

Removal of phagocytic cells with carbonyl iron. Phagocytic cells were removed from whole-blood aliquots with carbonyl iron (GAF Corporation, New York) as described by Lohrmann et al. (23). $80 \%$ of the monocytes were removed by this technique as determined microscopically (22).

Separation of E-rosetting cells. The method for rosette separation was a modification of the procedure described by Lohrmann et al. (23). $2.5 \times 10^{6}$ mononuclear cells (either unmanipulated, or previously treated with carbonyl iron) were mixed with $5 \times 10^{7}$ neuraminidase-(Vibrio cholerae neuraminidase, $50 \mathrm{U} / \mathrm{ml}$, Grand Island Biological Co.) treated sheep erythrocytes (Flow Laboratories, Rockville, Md.) and $0.25 \mathrm{ml}$ of fetal calf serum, centrifuged, and incubated at room temperature for $15 \mathrm{~min}$. The cell pellet was gently resuspended to avoid disrupting rosettes, and the light, nonrosetting cells were separated from the heavier, T-lymphocyte rosettes by centrifugation over Ficoll-Hypaque.

$80 \%$ of the E-rosetting cells were depleted from the nonrosetting fraction when retested with fresh neuraminidasetreated sheep erythrocytes. Both layers were retained, washed, and contaminating sheep erythrocytes were lysed by incubation in human plasma (which contains naturally occurring antibodies hemolytic for sheep erythrocytes) at $37^{\circ} \mathrm{C} \times 30$ min. These cells were twice washed in HBSS/albumin, and resuspended in TC 199/20\% plasma. Approximately 50\% of the E-rosetting cells present in the initial mononuclear cell suspension were recovered.

Cell cultures. Base-line, one-way, mixed lymphocyte cultures were established by adding $2 \times 10^{5}$ responder cells from Hodgkin's disease patients or normal controls (2A) and $4 \times 10^{5}$ fresh mitomycin C-treated allogeneic stimulator cells from a single normal donor $(4 \mathrm{Bm})$ in TC $199 / 20 \%$ plasma. For suppressor cultures, $16 \times 10^{5}$ additional cells autologous to the responder $(16 \mathrm{Am})$, and treated with mitomycin $\mathrm{C}$, were added. Approximately $80 \%$ of the cells initially present were recovered after treatment with mitomycin $\mathrm{C}$. Each experiment included unstimulated cultures, in which allogeneic cells were replaced with the same number of mitomycin C-treated autologous mononuclear cells (i.e., $2 \mathrm{~A}+4 \mathrm{Am}$ ). As an additional control, allogeneic combinations of mitomycin Ctreated cells were cultured to insure inhibition of proliferation by the treatment (i.e., $4 \mathrm{Am}+4 \mathrm{Bm}$ ). All cultures were performed in triplicate in $2 \mathrm{ml}$ in $12 \times 77-\mathrm{mm}$ polypropylene tubes (Falcon Plastics, Div. BioQuest, Oxnard, Calif.) and were incubated at $37^{\circ} \mathrm{C}$ in a humid environment in $5 \% \mathrm{CO}_{2}$.

At $120 \mathrm{~h}, 2 \mu \mathrm{Ci}$ of $\left[\right.$ methyl $-{ }^{3} \mathrm{H}$ ] thymidine $(6.7 \mathrm{Ci} / \mathrm{mmol}$, New England Nuclear, Boston, Mass.) were added and cultures were terminated $18 \mathrm{~h}$ later by addition of cold 5\% TCA. The resulting precipitate was washed, dissolved in NCS tissue solubilizer (Amersham Searle Corp., Arlington Heights, Ill.), and the radioactivity determined by liquid scintillation counting. The mean coefficient of variation for the triplicate cultures was $19.8 \%$.

Determination of autologous suppression. Net thymidine incorporation was determined by subtracting incorporation of unstimulated from stimulated cultures (thymidine incorporation in unstimulated cultures results in less than 1,500 cpm). Suppression was determined by the following formula, with net thymidine incorporation in all cases:

$$
\% \text { suppression }=1-\left(\frac{2 \mathrm{~A}+4 \mathrm{Bm}+16 \mathrm{Am}}{2 \mathrm{~A}+4 \mathrm{Bm}}\right) \times 100 .
$$


The thymidine incorporation of base-line mixed lymphocyte cultures is represented by $(2 \mathrm{~A}+4 \mathrm{Bm})$, and of "suppressor" cultures by $(2 \mathrm{~A}+4 \mathrm{Bm}+16 \mathrm{Am})$.

Determination of allogeneic suppression. Allogeneic suppression was determined by a modification of the procedure of Twomey et al. (10). Mitomycin C-treated mononuclear cells from Hodgkin's disease patients were added in mixed lymphocyte culture at two concentrations, $4 \times 10^{5}$ cells/culture $(4 \mathrm{Bm})$, and $16 \times 10^{5}$ cells/culture $(16 \mathrm{Bm})$. Responding mononuclear cells, from normal individuals, were added at $2 \times 10^{5}$ cells/ culture (2A). Suppression was determined by the following formula with net thymidine incorporation in all cases:

$$
\% \text { suppression }=1-\left(\frac{2 A+16 B m}{2 A+4 B m}\right) \times 100 \text {. }
$$

$(2 \mathrm{~A}+4 \mathrm{Bm})$ represents the base-line mixed lymphocyte culture, and uses the same cell number as in experiments involving autologous suppression. Suppressor cultures are rep- resented by $(2 \mathrm{~A}+16 \mathrm{Bm})$, and utilize the same number of Hodgkin's disease mitomycin C-treated mononuclear cells as in experiments demonstrating autologous suppression.

Statistical determinations. Statistical significance was determined by the Wilcoxon rank sum test, analysis of variance, and the paired $t$ test (24).

\section{RESULTS}

Suppressor cultures. The clinical characteristics of the patients with Hodgkin's disease are listed in Table I. In addition, net thymidine incorporation for the baseline and suppressor cultures are tabulated for the patients and for the 19 normal donors.

Fig. 1 illustrates the degree of mixed lymphocyte culture suppression produced by mononuclear cells

\section{TABLE I}

Clinical Characteristics and Mixed Lymphocyte Culture (MLC) Proliferative Response in Hodgkin's Disease Patients

\begin{tabular}{|c|c|c|c|c|c|c|c|c|}
\hline \multirow[b]{3}{*}{ Case no. } & \multicolumn{6}{|c|}{ Clinical characteristics } & \multirow{2}{*}{\multicolumn{2}{|c|}{$\left[{ }^{3} \mathrm{H}\right]$ Thymidine incorporation }} \\
\hline & \multirow[b]{2}{*}{ Age } & \multirow[b]{2}{*}{ Sex } & \multirow[b]{2}{*}{ Stage } & \multirow[b]{2}{*}{ Histology* } & \multirow{2}{*}{$\begin{array}{l}\text { Prior } \\
\text { therapyt }\end{array}$} & \multirow{2}{*}{$\begin{array}{l}\text { Last } \\
\text { therapy }\end{array}$} & & \\
\hline & & & & & & & Base-line MLC & Suppressor MLC \\
\hline & & & & & & & \multicolumn{2}{|c|}{ net $c p m \pm S E$} \\
\hline \multicolumn{9}{|c|}{ Active disease } \\
\hline \multicolumn{9}{|c|}{ Untreated } \\
\hline 1 & 31 & $\mathbf{M}$ & IA & NS & - & - & 34,387 & 8,595 \\
\hline 2 & 75 & $\mathbf{F}$ & IA & NS & - & - & 6,017 & 844 \\
\hline 3 & 29 & $\mathbf{F}$ & IA & NS & - & - & 48,069 & 14,233 \\
\hline 4 & 29 & $\mathbf{M}$ & IIA & NS & - & - & 44,693 & 23,381 \\
\hline 5 & 32 & $\mathrm{~F}$ & IIA & NS & - & - & 47,272 & 582 \\
\hline 6 & 33 & $\mathbf{M}$ & IIA & NS & - & - & 26,737 & 9,035 \\
\hline 7 & 18 & $\mathbf{F}$ & IIIA & NS & - & - & 32,640 & 17,356 \\
\hline 8 & 31 & $\mathrm{~F}$ & IIIA & NS & - & - & 62,086 & 10,059 \\
\hline 9 & 24 & $\mathbf{M}$ & IIIB & NS & - & - & 22,680 & 600 \\
\hline Mean & & & & & & & $36,061 \pm 5,533$ & $9,409 \pm 2,666$ \\
\hline \multicolumn{9}{|l|}{ Treated } \\
\hline 10 & 38 & $\mathbf{M}$ & IIAE & NS & RT & $4 \mathrm{yr}$ & 41,836 & 12,006 \\
\hline 11 & 62 & $\mathbf{M}$ & IIIB & NS & $\mathrm{RT}+\mathrm{CT}$ & $2 \mathrm{mo}$ & 7,221 & 954 \\
\hline 12 & 18 & $\mathbf{M}$ & IVB & NS & $\mathrm{RT}+\mathrm{CT}$ & $18 \mathrm{mo}$ & 7,716 & 2,197 \\
\hline 13 & 31 & $\mathbf{M}$ & IVB & NS & $\mathbf{R T}+\mathrm{CT}$ & $2 \mathrm{mo}$ & 3,802 & 51 \\
\hline 14 & 41 & $\mathbf{M}$ & IVB & NS & $\mathrm{RT}+\mathrm{CT}$ & $11 / 2 \mathrm{mo}$ & 5,154 & 764 \\
\hline Mean & & & & & & & $13,126 \pm 7,213$ & $3,194 \pm 2,230$ \\
\hline \multicolumn{9}{|c|}{ Remission disease } \\
\hline 15 & 28 & $\mathbf{F}$ & IIA & NS & RT & $3 \mathrm{yr}$ & 2,886 & 3,010 \\
\hline 16 & 44 & $\mathrm{~F}$ & IIA & NS & RT & $5 \mathrm{yr}$ & 12,181 & 3,741 \\
\hline 17 & 43 & $\mathbf{M}$ & IIA & MC & RT & $8 \mathrm{yr}$ & 53,553 & 34,066 \\
\hline 18 & 60 & $\mathbf{M}$ & IIA & MC & RT & $6 \mathrm{yr}$ & 31,873 & 14,409 \\
\hline 19 & 23 & $\mathbf{F}$ & IIIA & NS & RT & $6 \mathrm{yr}$ & 8,334 & 1,198 \\
\hline 20 & 31 & $\mathrm{~F}$ & IIIA & NS & $\mathrm{RT}+\mathrm{CT}$ & $11 / 2 \mathrm{mo}$ & 190,696 & 28,681 \\
\hline 21 & 32 & $\mathbf{M}$ & IIIA & NS & $\mathrm{RT}+\mathrm{CT}$ & $12 \mathrm{mo}$ & 15,827 & 2,269 \\
\hline 22 & 45 & $\mathbf{F}$ & IIIB & NS & $\mathbf{R T}+\mathrm{CT}$ & $9 \mathrm{mo}$ & 11,222 & 7,818 \\
\hline 23 & 57 & $\mathbf{M}$ & IVB & NS & $\mathrm{RT}+\mathrm{CT}$ & $3 \mathrm{mo}$ & 3,802 & 937 \\
\hline Mean & & & & & & & $36,708 \pm 17,869$ & $10,681 \pm 3,735$ \\
\hline \multicolumn{9}{|c|}{ Normal donors $\S$} \\
\hline Mean & & & & & & & $30,380 \pm 5,444$ & $24,118 \pm 4,851$ \\
\hline
\end{tabular}

* NS = nodular sclerosing. $\mathrm{MC}=$ mixed cellularity.

$\$ \mathrm{RT}=$ radiation therapy. $\mathrm{CT}=$ chemotherapy.

$\$ 19$ normal donors, 10 female, and 9 male. 


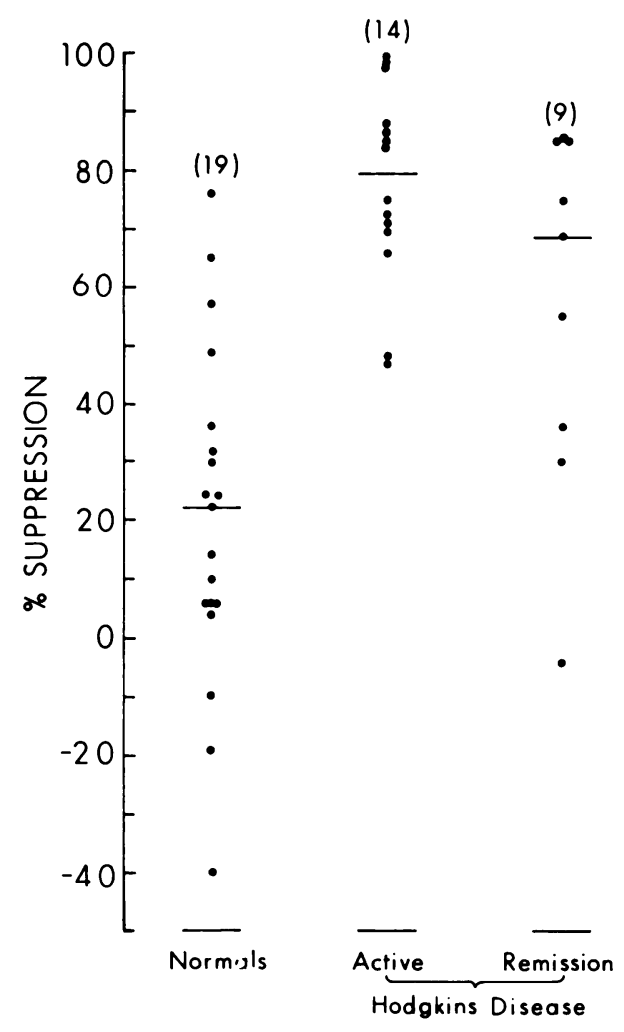

FIGURE 1 Mixed lymphocyte culture suppression in normals and patients with active and remission Hodgkin's disease. In individuals having multiple cultures, the percent suppression is calculated from the initial culture. The horizontal line in each column represents the median percent suppression. The number of subjects is in parentheses.

from patients with active Hodgkin's disease compared to remission Hodgkin's disease and normal controls. The mean percent suppression $( \pm \mathrm{SE})$ for the three groups are $(a)$ normals, $21 \% \pm 6.9 \%$; $(b)$ active Hodgkin's disease, $78 \% \pm 4.6 \%$; and $(c)$ remission Hodgkin's disease, $58 \% \pm 9.3 \%$. The difference between patients with active or remission Hodgkin's disease and normal controls is statistically significant $(P<0.01$ and $P$ $<0.05$, respectively). In Hodgkin's disease, although it appears that greater suppression is achieved with mononuclear cells from patients having active disease, the difference is not statistically significant.

Patients previously treated with chemotherapy and radiotherapy showed reduced reactivity in all cultures (Table I). However, prior treatment did not alter the degree of suppression as compared to untreated patients.

The degree of suppression in 14 patients with active Hodgkin's disease was compared by pathologic disease stage. Although the numbers in each category are too small for statistical comparison, increasing disease stage did not appear to enhance the suppressive effect of Hodgkin's disease mononuclear cells.
Having demonstrated increased suppressor activity in Hodgkin's disease patients, we next sought to clarify the mechanism of suppression. Because the suppressor cultures were at a higher cell density than the baseline cultures, it was necessary to determine whether changes in cell density alone alter the proliferative response. Dose-response curves in 12 normal donors were performed comparing the proliferative response of $2 \times 10^{5}$ mononuclear cells when stimulated with 4 , 16 , and $20 \times 10^{5}$ mitomycin-treated allogeneic cells (Fig. 2), corresponding to the cell density of the standard mixed lymphocyte culture and the suppressor cultures. The mean thymidine incorporation $( \pm S E)$ in counts per minute is $36,696 \pm 11,002,33,027 \pm 8,058$, and $58,884 \pm 23,046$, respectively. No suppression in proliferation was noted at the higher cell densities.

Effect of "suppressor" cells on normal allogeneic responder lymphocytes in mixed lymphocyte culture. In the foregoing studies, it was demonstrated that mitomycin C-treated mononuclear cells from patients with active Hodgkin's disease inhibit the proliferative capacity of their own lymphocytes. To determine their effect on normal, allogeneic lymphocytes, mitomycin C-treated mononuclear cells from patients with Hodgkin's disease were added to normal responding cells in mixed lymphocyte culture at two concentrations and percent suppression was calculated (see Methods).

Fig. 3 illustrates the results. In 8 of 10 Hodgkin's disease patients whose mononuclear cells exhibited autologous suppression, little or no inhibitory effect

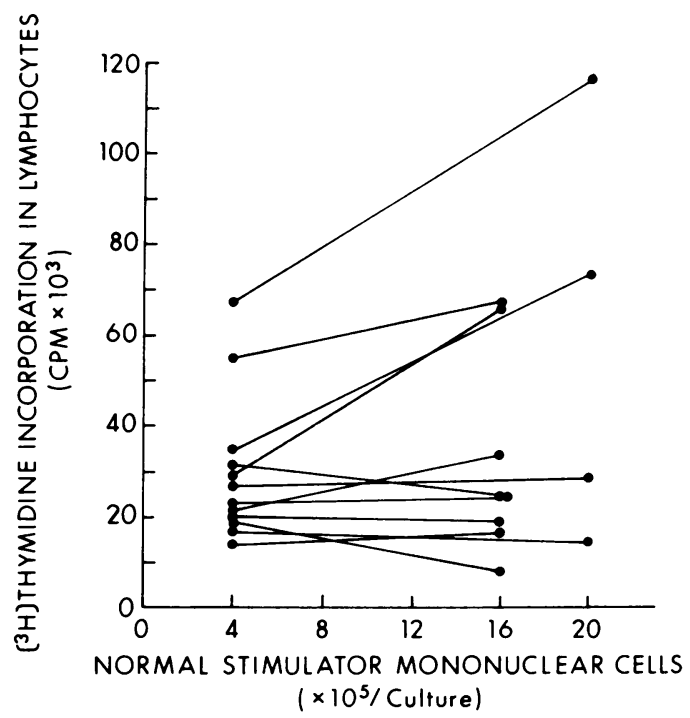

Figure 2 The effect of varying stimulator concentrations on mixed lymphocyte proliferation. Mononuclear cells from normal donors served as responder and stimulator cells. The incorporation of $\left[{ }^{3} \mathrm{H}\right]$ thymidine by $2 \times 10^{5}$-responder mononuclear cells is compared in mixed lymphocyte cultures by stimulator cell numbers of 4,16 , and $20 \times 10^{5}$. 


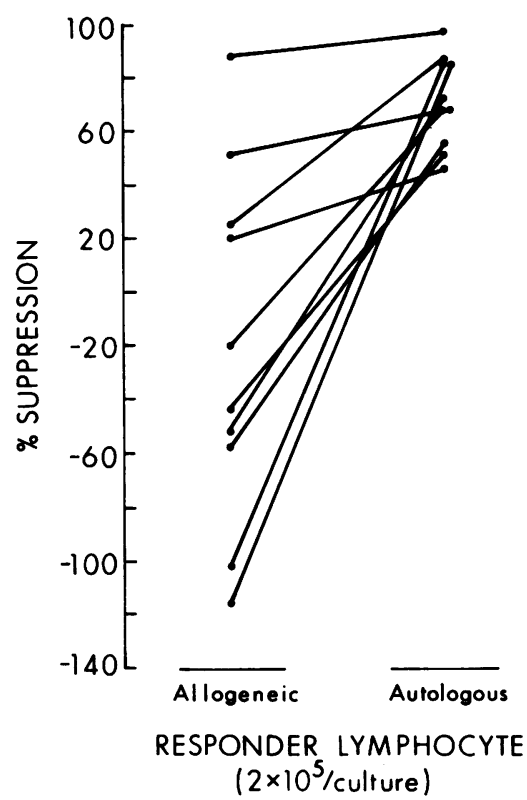

FIGURE 3 Suppression, by Hodgkin's disease mononuclear cells, of allogeneic and autologous responder lymphocytes. In the allogeneic culture system, responder cells obtained from normal donors were cultured with mononuclear cells from patients with Hodgkin's disease.

was noted on the proliferative response of allogeneic lymphocytes. The percent suppression $( \pm \mathrm{SE}$ ) of allogeneic and autologous lymphocytes was $-12.9 \%$ $\pm 20.9 \%$, and $71.9 \% \pm 5.3 \%$, respectively. This difference is statistically significant $(P<0.01)$.

Effect of "suppressor" cells on responding cells genotypically identical at the major histocompatability complex. In the earlier study, suppressor cells demonstrated very limited inhibition of unrelated lymphocytes. However, their effect on cells identical at the major histocompatibility complex was also evaluated. Patient no. 21 had an HLA $^{2}$ and mixed lymphocyte culture-identical sister. Table II shows the effect of suppression by the patient's and sister's mononuclear cells, on their own, each other's, and unrelated responder cells. The patient's cells demonstrated similar inhibition of both his own and his sister's lymphocyte response, but had no suppressive effect on the unrelated's cells. The sister's suppressor culture demonstrated modest autologous suppression, and inhibition of the patient's response to the same degree.

Effect of altering suppressor cell number. In one patient, the effect on proliferation of increasing numbers of "suppressor" cells was determined, keeping

${ }^{2}$ HLA typing of the patient, his parents, and five siblings was kindly performed by Dr. William Miller at the MissouriIllinois Regional Red Cross Blood Center, St. Louis, Mo. The patient and one sibling were found to be genotypically identical sharing the (A1, B15) and (A2, B12) haplotypes.
TABLE II

Suppression of Autologous, MLC-Identical, and Unrelated Responding Lymphocytes

\begin{tabular}{lccc}
\hline & \multicolumn{3}{c}{ Responder mononuclear cell } \\
\cline { 2 - 4 } & $\begin{array}{c}\text { Hodgkin's } \\
\text { disease } \\
\text { patient* }\end{array}$ & $\begin{array}{c}\text { MLC- } \\
\text { identical } \\
\text { sibling* }\end{array}$ & $\begin{array}{c}\text { Normal } \\
\text { individualt }\end{array}$ \\
\hline Suppressor cell donor & & $\% \pm S D$ & \\
$\begin{array}{c}\text { Hodgkin's disease } \\
\text { patient }\end{array}$ & $86 \pm 3$ & $82 \pm 4$ & $-102 \pm 62$ \\
$\begin{array}{c}\text { MLC-identical } \\
\text { sibling }\end{array}$ & $56 \pm 18$ & $68 \pm 6$ & - \\
\hline
\end{tabular}

* Suppressor cultures between the patient and sibling were performed with the technique for determining autologous suppression (see Methods), as their mononuclear cells were mutually nonstimulatory. Cells from an unrelated individual provided the culture's stimulus.

† Suppressor cultures where the responding cell was from the normal individual were performed by the technique for determining allogeneic suppression (see Methods).

both the responder and stimulator concentrations constant. A nearly linear fall in $\left[{ }^{3} \mathrm{H}\right]$ thymidine incorporation occurred as the concentration of "suppressor" cells was increased from 0 to $16 \times 10^{5}$ cells/culture.

Effect of altering culture incubation time. To exclude the possibility that suppression seen in our 6-day, mixed lymphocyte culture was simply because of alteration in the kinetics of the mixed lymphocyte culture, without a decline in peak reactivity, cultures were terminated on days 5,6 , and 7 . Suppression was similar over the 3-day period even though thymidine incorporation increased with increased culture time.

Identification of suppressor cells. Mononuclear cell suspensions from 10 patients were fractionated to identify the suppressor cell type. Evidence for lymphocyte-mediated suppression was noted in four patients. In two of these, mononuclear cell suspensions depleted of $>99 \%$ monocytes by nylon wool filtration showed no reduction in suppression, indicating the presence of suppressor lymphocytes (Table III, pts. 9 and 12). Additional evidence for lymphocyte-mediated suppression was obtained by E-rosette separation, without prior monocyte depletion. Removal of E-rosetting $T$ lymphocytes from the mononuclear cell suspension resulted in a loss of suppressor activity in two patients (Fig. 4). In one of these, the T-lymphocyte enriched fraction, after lysis of sheep erythrocytes, demonstrated enhanced suppressive ability. This fraction was not tested in the other patient.

In six patients, two studied by rosette separation, three by carbonyl iron-induced phagocyte depletion, and one with both techniques, the evidence suggested monocyte-mediated suppression. In three studies with rosette separation, the suppressor cell remained in 
TABLE III

Suppression of MLC by Mononuclear Cell Suspensions Depleted of Various Subpopulations

\begin{tabular}{rcccc}
\hline $\begin{array}{c}\text { Source of } \\
\text { mononuclear } \\
\text { cells (patient } \\
\text { number) }\end{array}$ & $\begin{array}{c}\text { Unfrac- } \\
\text { tionated }\end{array}$ & $\begin{array}{c}\text { Depleted of } \\
\text { adherent } \\
\text { cells }\end{array}$ & $\begin{array}{c}\text { Depleted of } \\
\text { phagocytic } \\
\text { cells }\end{array}$ & $\begin{array}{c}\text { Depleted of } \\
\text { E rosette- } \\
\text { forming } \\
\text { cells }\end{array}$ \\
\hline & & & $\%^{*}$ & \\
9 & 97 & 96 & -1 & - \\
12 & 72 & 69 & - & - \\
2 & 86 & - & - & 82 \\
13 & 99 & - & - & 94 \\
20 & 69 & - & $-18 \S$ & 58 \\
3 & 70 & - & -30 & - \\
6 & 66 & - & -44 & - \\
10 & 71 & - & -73 & - \\
\hline
\end{tabular}

* See Methods for calculations of percent suppression.

$\$$ Not tested.

$\$$ Negative values indicate stimulation rather than suppression.

the non-E-rosette population (Table III, pts. 2, 13, and 20). This fraction contained all the monocytes and the rosette-depleted lymphocytes. Subsequently, in four studies, with phagocytic cells depleted by carbonyl iron, removal of the suppressor population was demonstrated (Table III, pts. 20, 3, 6, and 10). In addition, mononuclear cells from one of the patients (no. 20), after monocyte depletion by nylon wool filtration, lost suppressor activity (data not shown).

To exclude nonspecific toxicity to suppressor cells by carbonyl iron, a patient with lymphocytic suppressor cells was studied. Suppression was demonstrated in the nonadherent fraction after nylon wood filtration. Suppression was maintained at a comparable level after removal of phagocytic cells with carbonyl iron.

Lastly, the increased suppression seen in Hodgkin's disease patients is not explained by an increase in monocytes. The mean percentage of monocytes $( \pm S D)$ in mononuclear cell suspensions determined microscopically by supravital staining is as follows: normal donors, $17 \% \pm 10.8 \%$; active Hodgkin's disease (with monocyte suppressors), $23 \% \pm 11.9 \%$. This is not a statistically significant difference.

\section{DISCUSSION}

The existence of suppressor cells and their role in modifying the immune response has been appreciated only recently. Gershon, who coined the term "suppressor T cell," has reviewed many of their known interactions (25). Murine models have provided the principal framework for studying these interactions, and both thymus-derived lymphocytes and monocytes have shown suppressor functions (26-30).

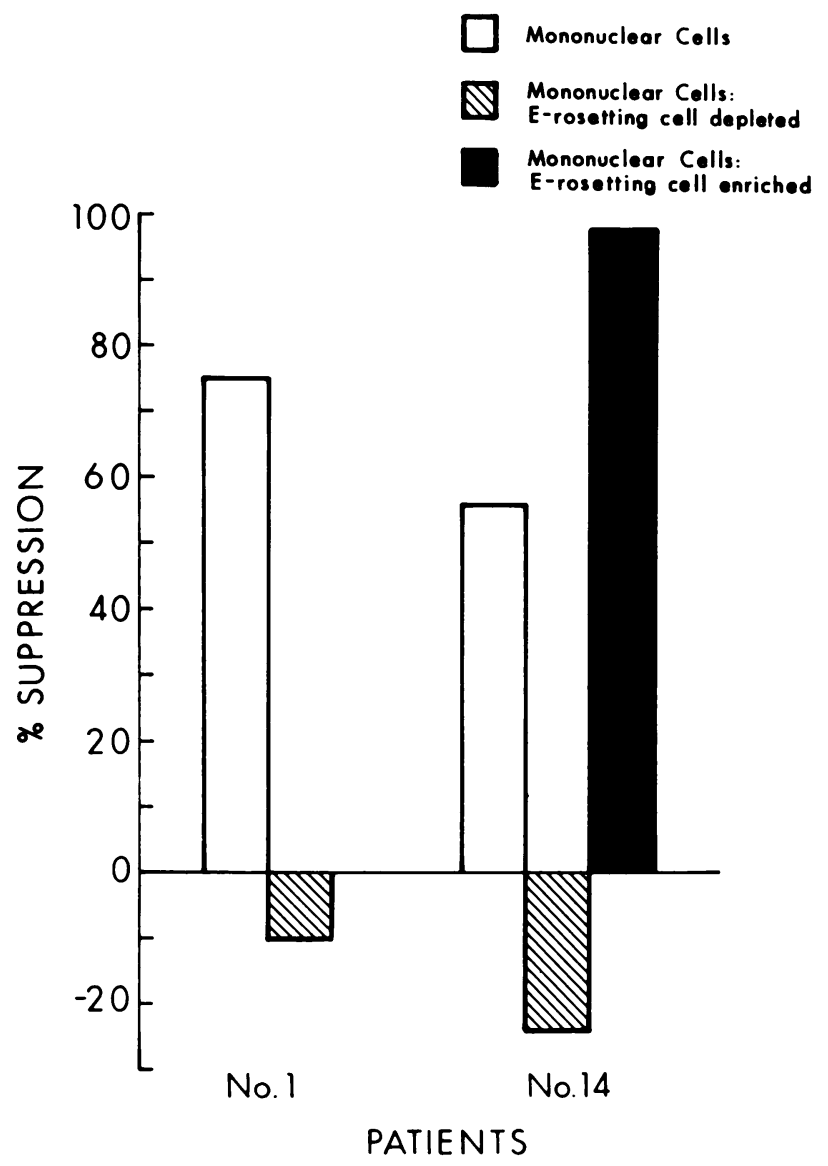

FIgURE 4 Mixed lymphocyte culture suppression by E-rosetting lymphocytes. Suppressor cultures with E rosette-depleted and $\mathrm{E}$ rosette-enriched mononuclear cells are compared with unmanipulated cells.

In the present study we describe a modified mixed lymphocyte culture technique which can be used to demonstrate active cell-mediated suppression. With this technique we have demonstrated the presence of increased suppressor activity in the majority of patients with Hodgkin's disease compared to normal controls. Suppressor activity could not be correlated with either disease stage or prior treatment of the patients. Evidence has been presented to show that the reduction in lymphocyte proliferation observed in suppressor cultures is not due simply to the increased cell density or depletion of nutritional factors, and is linearly related to the number of suppressor mononuclear cells present.

A recent study by Goodwin and his associates (31) indicates that suppression of the response to phytohemagglutinin may result from increased production of prostaglandin $E_{2}$ by mononuclear cells from patients with Hodgkin's disease, and can be prevented by adding indomethacin to the cultures. The effect of indo- 
methacin on mixed lymphocyte culture suppression remains to be determined. However, in preliminary experiments, we have been unable to demonstrate the presence of a soluble mediator or suppression (such as prostaglandin $\mathrm{E}_{2}$ ) in supernates of suppressor cultures.

Several separation techniques were employed to identify the suppressor cell. Evidence for lymphocytemediated suppression was obtained in 4 of 10 patients studied: In two instances suppressor activity was not impaired by removal of nylon wool adherent cells, a technique that removed $>99 \%$ of the monocytes, leaving only lymphocytes. In two additional studies, depletion of T lymphocytes by removal of E-rosette-forming cells abolished suppressor activity, which was shown to reside in the E-rosetting fraction. A thymusdependent suppressor mechanism responsible for impaired cellular immunity also has been described in studies of patients with myasthenia gravis (32) and disseminated fungal infections (33).

In six patients suppression appeared not to be mediated by $\mathrm{T}$ lymphocytes. This conclusion is based on the failure of E-rosette depletion to alter suppression in three instances, whereas depletion of phagocytic cells by carbonyl iron removed suppressor activity in four studies. It should be emphasized that only one of these patients was studied by both techniques; in this case depletion of phagocytic cells removed suppressor activity and depletion of E-rosetting cells was without effect. In the remaining patients the possibility that both $\mathrm{T}$ lymphocytes and monocytes are required for suppression cannot be excluded. Our findings differ from those of Twomey et al. who found suppressor cells in Hodgkin's disease patients to be adherent but not phagocytic (10). In the two patients we studied by both techniques, depletion of phagocytic cells and depletion of adherent cells produced the same results. Other investigators also have described a phagocytic suppressor cell in Hodgkin's disease patients (17). These differing results may be explained by differences in the patient populations under study as well as different methods of determining suppression.

An interesting feature of T-cell-mediated suppression in murine systems is the apparent restriction of suppression to cells which share I-region specificities (27). A similar genetic restriction of suppression in Hodgkin's disease patients is suggested by our finding that mononuclear cells from patients with marked suppression of autologous lymphocyte proliferation were capable of little or no suppression of allogeneic lymphocytes. Although a modest degree of suppression might be masked by increased stimulation because of the large number of allogeneic "suppressor" cells, culture conditions have been chosen to minimize this possibility by the use of stimulating cell doses in control cultures that produce a nearly maximal response. In contrast, suppressor cultures involving a Hodgkin's dis- ease patient and an HLA genotypically identical sibling showed equivalent suppression. Additional studies are needed to clarify the required degree of identity at the major histocompatibility complex.

Lastly, we have found that mononuclear cells from normal individuals may demonstrate autologous suppression. Similar to the results obtained with Hodgkin's disease patients, the removal of either phagocytic cells or T lymphocytes in several normal donors demonstrating suppression eliminated the inhibitory effect (results not shown). Shou et al. (34) have previously demonstrated "latent" inhibitory lymphocytes in humans, inducible only by preincubation with concanavalin A, that diminish the proliferative capacity of allogeneic and autologous lymphocytes. Sampson et al. (35), with a culture system similar to ours, showed suppression of both autologous and allogeneic responders in mixed lymphocyte cultures by human spleen cells previously incubated with concanavalin A or phytohemagglutinin, but not by untreated cells. This evidence suggests the existence of suppressor cells in normal individuals which may be demonstrated under certain culture conditions or induced by prior mitogen stimulation. It is likely that cell-mediated suppression represents an important control mechanism of the normal immune response which is altered in a variety of disease states.

\section{ACKNOWLEDGMENTS}

We wish to express appreciation to Dr. Edward H. Reinhard for referring most of the patients, to Miss Mary C. Beranek for her technical assistance, and to Mr. Frederic S. Green III for help with the statistical analysis.

This study was supported by the Division of Cancer Research, National Cancer Institute, grant no. CA-03376.

\section{REFERENCES}

1. Case, D. C., J. A. Hansen, E. Corrales, C. W. Young, B. DuPont, C. M. Pinsky, and R. A. Good. 1976. Comparison of multiple in vivo and in vitro parameters in untreated patients with Hodgkin's disease. Cancer (Phila.). 38: $1807-1815$.

2. Graze, P. R., E. Perlin, and I. Royston. 1976. In vitro lymphocyte dysfunction in Hodgkin's disease. J. Natl. Cancer Inst. 56: 239-243.

3. Miller, D. G., J. G. Lizardo, and R. K. Snyderman. 1961. Homologous and heterologous skin transplantation in patients with lymphomatous disease. J. Natl. Cancer Inst. 26: $569-579$.

4. Eltringham, J. R., and H. S. Kaplan. 1973. Impaired delayed hypersensitivity response in 154 patients with untreated Hodgkin's disease. Natl. Cancer Inst. Monogr. 36: $107-115$.

5. Green, I., and P. F. Corse. 1959. A study of skin homografting in patients with lymphomas. Blood. 14: 235-245.

6. Skal, J. E., and N. Primikivios. 1961. The delayed skin test response in Hodgkin's disease and lymphosarcoma. Cancer (Phila.). 14: 597-607.

7. DeGast, G. C., M. R. Halie, and H. O. Nieweg. 1975. Immunological responsiveness against two primary anti- 
gens in untreated patients with Hodgkin's disease. Eur. J. Cancer. 11: 217-224.

8. Levy, R., and H. S. Kaplan. 1974. Impaired lymphocyte function in untreated Hodgkin's disease. N. Engl. J. Med. 290: $181-186$.

9. Björkholm, M., G. Holm, H. Mellstedt, and D. Pettersson. 1976. Immunological capacity of lymphocytes from untreated patients with Hodgkin's disease evaluated in mixed lymphocyte culture. Clin. Exp. Immunol. 22: 373377.

10. Twomey, J. J., A. H. Laughter, S. Farrow, and C. C. Douglass. 1975. Hodgkin's disease: An immunodepleting and immunosuppressive disorder. J. Clin. Invest. 56: 467475.

11. Bobrove, A. M., Z. Fuks, S. Strober, and H. S. Kaplan. 1975. Quantitation of T and B lymphocytes and cellular immune function in Hodgkin's disease. Cancer (Phila.). 36: 169-179.

12. Cohnen, G., W. Augener, G. Brittinger, and S. D. Douglas. 1973. Rosette-forming lymphocytes in Hodgkin's disease. N. Engl. J. Med. 289: 863.

13. Fuks, Z., S. Strober, and H. S. Kaplan. 1976. Interaction between serum factors and T-lymphocytes in Hodgkin's disease. N. Engl. J. Med. 295: 1273-1278.

14. Waldmann, T. A., S. Broder, M. Darm, R. M. Blaese, M. Blackman, and W. Strober. 1974. Role of suppressor T cells in pathogenesis of common variable hypogammaglobulinemia. Lancet. II: 609-613.

15. Siegal, R. P., M. Siegal, and R. A. Good. 1976. Suppression of B-cell differentiation by leukocytes from hypogammaglobulinemic patients. J. Clin. Invest. 58: 109-122.

16. Broder, S., R. Humphrey, M. Durm, M. Blackman, B. Meade, C. Goldman, W. Strober, and T. Waldmann. 1975. Impaired synthesis of polyclonal (non-paraprotein) immunoglobulins by circulating lymphocytes from patients with multiple myeloma (role of suppressor cells). N. Engl. J. Med. 293: 887-892.

17. Schechter, G. D., and F. Soehnler. 1976. Monocyte-mediated inhibition of lymphocyte blastogenesis associated with peripheral blood monocytosis in Hodgkin's disease and tuberculosis. 19th Annual Meeting, American Society of Hematology. 82. (Abstr.)

18. Lukes, R. J., L. F. Craver, T. C. Hall, H. Rappaport, and P. Rubin. 1966. Part 1. Report of the Nomenclature Committee. Cancer Res. 26: 1311.

19. Carbone, P. P., H. S. Kaplan, K. Musshoff, D. W. Smithers, and M. Tubiana. 1971. Report of the committee on Hodgkin's disease staging classification. Cancer Res. 31: 18601861.

20. Böyum, A. 1968. Isolation of mononuclear cells and granulocytes from human blood. Scand. J. Clin. Lab. Invest. 21(Suppl. 97): 77-89.

21. Mendelsohn, J., S. A. Skinner, and S. Kornfeld. 1971. The rapid induction by phytohemagglutinin of increased $\alpha$ aminoisobutyric acid uptake by lymphocytes. J. Clin. Invest. 50: 818-826.

22. Cunningham, R. S., and E. H. Tompkins. 1930. The supravital staining of normal human blood cells. Folia Haematol. (Leipz.). 42: 257-269.

23. Lohrmann, H. P., L. Novikous, and R. G. Graw, Jr. 1974. Cellular interactions in the proliferative response of human $\mathrm{T}$ and $\mathrm{B}$ lymphocytes to phytomitogens and allogeneic lymphocytes. J. Exp. Med. 139: 1553-1567.

24. Klugh, H. E. 1970. Statistics - The Essentials for Research. John Wiley and Sons, Inc. New York. 185-190, $231,301$.

25. Gershon, R. K. 1975. A disquisition on suppressor T cells. Transplant Rev. 26: 170-185.

26. Rich, S. S., and R. R. Rich. 1974. Regulatory mechanisms in cell-mediated immune responses. I. Regulation of mixed lymphocyte reactions by alloantigen-activated thymus-derived lymphocytes. J. Exp. Med. 140: 15881603.

27. Rich, S. S., and R. R. Rich. 1975. Regulatory mechanisms in cell-mediated immune responses. II. A genetically restricted suppressor of mixed lymphocyte reaction released by alloantigen-activated spleen cells. J. Exp. Med. 142: $1391-1402$.

28. Rich, S. S., and R. R. Rich. 1976. Regulatory mechanisms in cell-mediated immune responses. IV. Expression of a receptor for mixed lymphocyte reaction suppressor factor on activated T lymphocytes. J. Exp. Med. 144: 1214-1226.

29. Eggers, A. E., and J. R. Wunderlick. 1975. Suppressor cells in tumor-bearing mice capable of non-specific blocking of in vitro immunization against transplantation antigens. J. Immunol. 114: 1554-1556.

30. Kirchener, H., A. V. Muchmore, T. M. Chused, H. T. Holden, and R. B. Herberman. 1975. Inhibition of proliferation of lymphoma cells and T-lymphocytes by suppressor cells from spleens of tumor-bearing mice. J. Immunol. 114: 206-210.

31. Goodwin, J. S., R. P. Messner, A. D. Bankhurst, G. T. Peake, J. Saiki, and R. C. Williams, Jr. 1977. Prostaglandin-producing suppressor cells in Hodgkin's disease. $N$. Engl. J. Med. 297: 963-968.

32. Birnbaum, G., and P. Tsairis. 1976. Suppressor lymphocytes in myasthenia gravis and effect of adult thymectomy. Ann. N. Y. Acad. Sci. 274: 527-535.

33. Stobo, J. D., S. Paul, R. E. Lan, and P. E. Hermans. 1976. Suppressor thymus-derived lymphocytes in fungal infections. J. Clin. Invest. 57: 319-328.

34. Shou, S., S. S. Schwartz, and R. A. Good. 1976. Suppressor cell activity after concanavalin A treatment of lymphocytes from normal donors. J. Exp. Med. 143: 1100-1110.

35. Sampson, D., G. Grotelueschen, and H. M. Kauffman, Jr. 1975. The human splenic suppressor cell. Transplantation (Baltimore). 20: 362-367. 